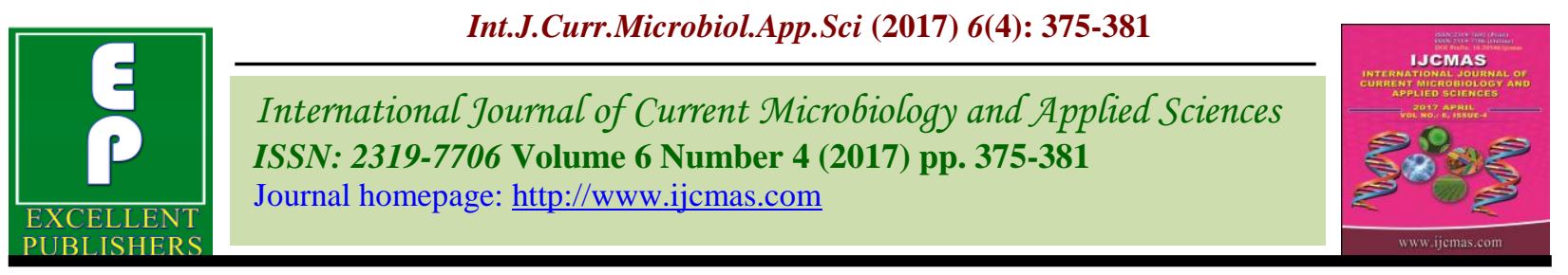

Original Research Article https://doi.org/10.20546/ijcmas.2017.604.042

\title{
Vertical Distribution of Nutrient of the Soils of Namblan Sub-Catchment of Jhelum Basin of Srinagar District in Kashmir Valley
}

\author{
Mehraj U.D. Din Khanday*, D. Ram, J.A. Wani and Tahir Ali \\ Division of Soil Science SKUAST-K Shalimar, Srinagar-190025, India \\ *Corresponding author
}

\author{
A B S T R A C T
}

\section{Keywords}

Sub-catchment, Nutrients,

Micronutrients, Soil, Analyzed.

Article Info

\section{Accepted:}

02 March 2017

Available Online:

10 April 2017
Among the various Sub-catchments in the state of Jammu and Kashmir, the Namblan Subcatchment of Jhelum basin has not been studied in view of the nutrient status of the soils. Based on variations in vegetation, altitude, land use and soil heterogeneity six representative soil profiles were exposed and studied for their depth wise distribution of Nutrient. Soil samples collected thereof, were analyzed for various macro and micro nutrients. While as the increasing trend was followed by the macro-nutrients and micro nutrients. The contents of nitrogen and potassium were in the range of 231.43 to 585.38 and 210.43 to $572.45 \mathrm{~kg} \mathrm{ha}^{-1}$ with the mean values of 376.41 and $371.87 \mathrm{~kg} \mathrm{ha}^{-1}$, respectively. Whereas phosphorus and sulphur ranged from 15.95 to 24.86 and 13.42 to $22.67 \mathrm{~kg} \mathrm{ha}^{-1}$ with a mean value of 20.60 and $18.83 \mathrm{~kg} \mathrm{ha}^{-1,}$ the content of $\mathrm{Zn}$ and $\mathrm{Cu}$ were in the range of 0.88 to $2.34 \mathrm{mg} \mathrm{kg}^{-1}$ and 0.97 to $2.66 \mathrm{mg} \mathrm{kg}^{-1}$ with a mean value of 1.50 to $1.69 \mathrm{mg} \mathrm{kg}^{-1}$, respectively. Whereas, iron and manganese contents were in the range of 18.45 to $42.26 \mathrm{mg} \mathrm{kg}^{-1}$ and 15.12 to $40.06 \mathrm{mg} \mathrm{kg}^{-1}$ with a mean value of 31.10 and 28.28 $\mathrm{mg} \mathrm{kg}^{-1}$ respectively. The contents varied from medium to high and also decreased with the depth.

\section{Introduction}

The present study was aimed to see the Vertical distribution of Nutrient of the soils of Namblan Sub-catchment of Jhelum Basin of Srinager district in Kashmir valley in the year 2011-12. Based on physiography, land use and altitude 6 soil profiles were exposed and studied for their nutrients status and samples collected thereof were analyzed for various macro and micronutrients. The Dal catchment is spread over an area of $395 \mathrm{sq}$. $\mathrm{km}$. with two sub-catchments viz., Namblan and Dara. The Namblan sub-catchment selected for study is comprised of two watersheds viz., Z1a (1049.5 ha) and Z1b (7488 ha) which have already been identified by the Directorate of
Soil and Water Conservation, $\mathrm{J}$ and $\mathrm{K}$ Government. The Namblan subcatchment falls along the north in district Srinagar of Kashmir valley. It lies between $34^{\circ} 09^{\prime}$ to $34^{\circ} 14^{\prime} \mathrm{N}$ latitude and $74^{\circ} 49^{\prime}$ to $75^{\circ} 09^{\prime} \mathrm{E}$ longitude. The mean elevation of area is about $2348 \mathrm{~m}$ amsl.

The soils are shallow to deep, mostly loam to silty loam and silty clay to clay. Soils are slightly acidic to neutral in reaction, low to high in organic carbon and medium to high in available nutrients. The wide variation in soil characteristics are mostly associated with variation in slope, vegetation cover, parent 
material and slope aspect. The soils are mostly subjected to moderate to severe erosion and have moderate surface stoniness at some places and these patches are dominantly associated with rock outcrops.

As the interface between the atmosphere, biosphere, and lithosphere, soil undergoes an intense vertical exchange of materials resulting in steep chemical and physical gradients from surface to bedrock. Soil stratification is the most visible result of this exchange, and its extensive observation and synthesis form the basis of pedogenetic and taxonomic study (Hilgard, 1906; Jenny, 1941; Soil Survey Staff, 1975; Buol et al., 1989). The type, thickness, and position of horizons can yield information about soil forming factors such as climate, topography, and vegetation type (Jenny, 1941; Marion et al., 1985; Honeycutt et al., 1990). Likewise, the vertical distribution of soil nutrients should yield similar insights into nutrient inputs, outputs, and cycling processes (Smeck, 1973; Kirby, 1985). The goals of this paper are first to characterize the vertical distribution of nutrients globally and second to evaluate the importance of plant cycling for structuring soil nutrients vertically.

\section{Materials and Methods}

We restricted our analysis to profiles with a complete description of an element. Surface litter layers were not considered in the analyses. Profiles with three or fewer horizons in the top meter were eliminated because there was insufficient detail to characterize vertical distributions. $\mathrm{pH}$ where determined by the method followed by Jackson (1973). While as Available nitrogen was estimated by alkaline potassium permanganate method as given by Subbiah and Asija (1956). The available phosphorus was extracted by $0.5 \mathrm{M}$ $\mathrm{NaHCO}_{3}$ at $\mathrm{pH} 8.5$ and colour developed by stannous chloride was measured with the help of spectrophotometer at $660 \mathrm{~nm}$ wave length (Olsen and Sommers, 1982). The available potassium was extracted by $1 \mathrm{~N}$ ammonium acetate at pH 7 and then determined with the help of flame photometer (Jackson, 1973). Available sulphur was determined turbidimetrically as Barium sulphate by the method of Chesnin and Yein (1950). While as The micronutrient estimation was done by using the method outlined by Lindsay and Norvell (1978) using Atomic Absorption Spectrophotometer (AAS).

\section{Results and Discussion}

On the whole, the soils were acidic to neutral in soil reaction with $\mathrm{pH}$ ranging from 5.35 to 6.93. The $\mathrm{pH}$ generally increased with increasing depth. The increase in $\mathrm{pH}$ with depth had been attributed to leaching of bases and decrease in organic matter accumulation with the extent of slope. Its lowest values were observed in forest soils followed by orchards. This may be due to the formation of organic acids from organic matter upon decomposition which eventually lowers down the $\mathrm{pH}$ of the soil. Similar finding were observed by Rajeswar and Khan (2008)

Perusal of data in table 1 presented in revealed that the amount of available nitrogen and potassium ranged from medium to high and decreased with the depth. The contents of nitrogen and potassium were in the range of 231.43 to 585.38 and 210.43 to $572.45 \mathrm{~kg} \mathrm{ha}^{-1}$ with the mean values of 376.41 and $371.87 \mathrm{~kg}$ $\mathrm{ha}^{-1}$, respectively. Whereas phosphorus and sulphur ranged from 15.95 to 24.86 and 13.42 to $22.67 \mathrm{~kg} \mathrm{ha}^{-1}$ with a mean value of 20.60 and $18.83 \mathrm{~kg} \mathrm{ha}^{-1}$, respectively. The graphical representation of the macro nutrients is shown in figure $1 \mathrm{a}$ and $\mathrm{b}$. Both decreased with the depth and ranged from medium to high in all the profiles. The available nitrogen content was found medium to high in all the soil profiles which can be attributed to the high 
organic carbon content in the soils. Also a decreasing trend with the depth was observed in all the profiles due to decrease in organic matter with the increasing depth. The results are in close conformity with the findings of Talib and Verma (1990) and Selvaraj and Naidu (2012).

The available phosphorus content observed was medium to high in all the profiles which slightly decreased with increasing depth.
However, the higher values of available phosphorus content were observed in the surface horizons. This might be due to the presence of organic matter which increases the availability of phosphorus in soil (Singh and Mishra, 2012). The lower phosphorus content in sub surface horizons could be attributed to the fixation of released phosphorus by clay minerals and oxides of iron and aluminum (Thangasamy et al., 2005 and Nazir and Wani, 2009).

Table.1 Macronutrient status of Namblan sub catchment of Jhelum basin

\begin{tabular}{|c|c|c|c|c|c|c|}
\hline \multirow{2}{*}{ Profile } & \multirow{2}{*}{$\begin{array}{c}\text { Horizo } \\
\mathbf{n}\end{array}$} & \multirow{2}{*}{$\begin{array}{l}\text { Depth } \\
(\mathrm{cm})\end{array}$} & \multicolumn{4}{|c|}{ Macronutrients $\left(\mathrm{kg} \mathrm{ha}^{-1}\right)$} \\
\hline & & & $\mathbf{N}$ & $\mathbf{P}$ & $\mathbf{K}$ & $\mathbf{S}$ \\
\hline \multirow{5}{*}{$\begin{array}{l}\mathrm{P}_{1} \text { (Taki-i- } \\
\text { Nizame) }\end{array}$} & Ap & $0-17$ & 585.38 & 23.16 & 494.05 & 18.44 \\
\hline & Bw1 & $17-38$ & 559.64 & 22.15 & 490.83 & 18.39 \\
\hline & $\mathrm{Bw} 2$ & $38-49$ & 494.30 & 20.92 & 470.92 & 17.67 \\
\hline & Bw3 & $49-70$ & 489.17 & 19.91 & 450.51 & 17.18 \\
\hline & $\mathrm{BC}$ & $70-85$ & 482.34 & 19.62 & 430.37 & 16.91 \\
\hline \multirow{3}{*}{$\begin{array}{l}\mathrm{P}_{2} \\
\text { (Cheshmashahi) }\end{array}$} & $\mathrm{A}$ & $0-25$ & 493.52 & 20.12 & 253.24 & 20.43 \\
\hline & $\mathrm{C} 1$ & $25-48$ & 403.60 & 18.68 & 210.43 & 19.44 \\
\hline & $\mathrm{C} 2$ & $48-55$ & 336.76 & 17.00 & 214.33 & 19.20 \\
\hline \multirow[t]{5}{*}{$\mathrm{P}_{3}$ (Namblan) } & A & $0-17$ & 320.16 & 24.86 & 438.30 & 22.67 \\
\hline & $\mathrm{Bt} 1$ & $10-27$ & 311.43 & 24.39 & 425.87 & 22.15 \\
\hline & $\mathrm{Bt} 2$ & $27-44$ & 290.52 & 23.90 & 415.92 & 21.66 \\
\hline & $\mathrm{Bt} 3$ & $44-65$ & 271.22 & 23.63 & 405.15 & 20.92 \\
\hline & $\mathrm{C}$ & $65-110$ & 231.43 & 22.38 & 382.26 & 18.41 \\
\hline \multirow{5}{*}{$\mathrm{P}_{4}$ (Vasanpur) } & A & $0-15$ & 515.47 & 18.44 & 310.21 & 16.93 \\
\hline & Bw1 & $15-38$ & 471.16 & 18.66 & 291.21 & 15.95 \\
\hline & $\mathrm{Bw} 2$ & $38-60$ & 381.07 & 18.19 & 270.31 & 13.80 \\
\hline & $\mathrm{Bw} 3$ & $60-75$ & 337.14 & 16.69 & 253.24 & 13.69 \\
\hline & $\mathrm{C}$ & $\begin{array}{l}75-90 \\
\end{array}$ & 315.21 & 15.95 & 220.21 & 13.42 \\
\hline \multirow[t]{3}{*}{$\mathrm{P}_{5}$ (Pahlipora) } & A & $0-16$ & 408.69 & 22.69 & 572.45 & 22.24 \\
\hline & B & $16-38$ & 377.08 & 22.65 & 518.94 & 21.41 \\
\hline & $\mathrm{C}$ & $38-70$ & 359.00 & 22.15 & 405.22 & 21.41 \\
\hline \multirow{5}{*}{$\mathrm{P}_{6}$ (Shalimar) } & $\mathrm{Ap}$ & $0-15$ & 309.59 & 21.66 & 397.24 & 22.65 \\
\hline & Bw1 & $15-26$ & 285.17 & 20.63 & 379.03 & 20.52 \\
\hline & Bw2 & $26-48$ & 262.44 & 20.14 & 363.17 & 19.67 \\
\hline & $\mathrm{Bw} 3$ & $\begin{array}{l}48-74 \\
\end{array}$ & 253.12 & 18.39 & 326.12 & 18.39 \\
\hline & $\mathrm{C}$ & $74-120$ & 242.31 & 18.61 & 279.12 & 16.15 \\
\hline \multicolumn{3}{|c|}{ Mean } & 376.41 & 20.60 & 371.87 & 18.83 \\
\hline
\end{tabular}


Int.J.Curr.Microbiol.App.Sci (2017) 6(4): 375-381

Table.2 Micro nutrient status of Namblan sub catchment of Jhelum basin

\begin{tabular}{|c|c|c|c|c|c|c|}
\hline \multirow{2}{*}{ Profile } & \multirow{2}{*}{ Horizon } & \multirow{2}{*}{$\begin{array}{l}\text { Depth } \\
\text { (cm) }\end{array}$} & \multicolumn{4}{|c|}{ Micronutrients (mg/kg) } \\
\hline & & & $\mathbf{Z n}$ & $\mathbf{C u}$ & $\mathbf{F e}$ & Mn \\
\hline \multirow{5}{*}{$\begin{array}{l}\mathrm{P}_{1} \text { (Taki-i- } \\
\text { Nizame) }\end{array}$} & Ap & $0-17$ & 2.33 & 2.66 & 41.31 & 38.46 \\
\hline & Bw1 & $17-38$ & 1.97 & 2.01 & 37.26 & 35.87 \\
\hline & Bw2 & $38-49$ & 1.34 & 1.38 & 34.65 & 33.86 \\
\hline & Bw3 & $49-70$ & 1.02 & 1.26 & 31.67 & 28.03 \\
\hline & $\mathrm{BC}$ & $70-85$ & 0.95 & 1.67 & 29.46 & 25.67 \\
\hline \multirow{3}{*}{$\begin{array}{l}\mathrm{P}_{2} \\
\text { (Cheshmashahi) }\end{array}$} & A & $0-25$ & 1.36 & 2.54 & 41.35 & 39.06 \\
\hline & $\mathrm{C} 1$ & $25-48$ & 0.92 & 1.46 & 38.26 & 36.26 \\
\hline & $\mathrm{C} 2$ & $48-55$ & 0.88 & 0.97 & 35.31 & 32.21 \\
\hline \multirow[t]{5}{*}{$\mathrm{P}_{3}$ (Namblan) } & A & $0-17$ & 2.34 & 2.18 & 34.06 & 32.84 \\
\hline & Bt1 & $10-27$ & 2.31 & 2.01 & 32.65 & 28.86 \\
\hline & $\mathrm{Bt} 2$ & $27-44$ & 1.46 & 1.84 & 28.46 & 25.67 \\
\hline & $\mathrm{Bt} 3$ & $44-65$ & 0.96 & 1.57 & 23.32 & 20.87 \\
\hline & $\mathrm{C}$ & $65-110$ & 1.03 & 1.68 & 18.45 & 17.67 \\
\hline \multirow[t]{5}{*}{$\mathrm{P}_{4}$ (Vasanpur) } & A & $0-15$ & 1.63 & 1.68 & 37.65 & 32.45 \\
\hline & Bw1 & $15-38$ & 1.89 & 1.38 & 32.67 & 30.78 \\
\hline & Bw2 & $38-60$ & 1.03 & 1.26 & 26.45 & 21.78 \\
\hline & Bw3 & $60-75$ & 0.96 & 1.32 & 25.42 & 19.89 \\
\hline & $\mathrm{C}$ & $75-90$ & 0.88 & 1.18 & 25.91 & 23.67 \\
\hline \multirow[t]{3}{*}{$\mathrm{P}_{5}$ (Pahlipora) } & A & $0-16$ & 2.01 & 2.11 & 42.26 & 40.06 \\
\hline & B & $16-38$ & 1.63 & 1.81 & 37.21 & 35.46 \\
\hline & $\mathrm{C}$ & $38-70$ & 1.89 & 1.73 & 34.31 & 32.21 \\
\hline \multirow[t]{5}{*}{$\mathrm{P}_{6}$ (Shalimar) } & Ap & $0-15$ & 2.34 & 1.84 & 29.83 & 25.22 \\
\hline & Bw1 & $15-26$ & 2.31 & 1.81 & 25.34 & 23.21 \\
\hline & Bw2 & $26-48$ & 1.46 & 1.68 & 24.21 & 21.86 \\
\hline & Bw3 & $48-74$ & 0.96 & 1.51 & 21.76 & 18.34 \\
\hline & $\mathrm{C}$ & $74-120$ & 1.03 & 1.52 & 19.43 & 15.12 \\
\hline \multicolumn{3}{|c|}{ Mean } & 1.50 & 1.69 & 31.10 & 28.28 \\
\hline
\end{tabular}


Fig.1 Graphical representation of the macro nutrients
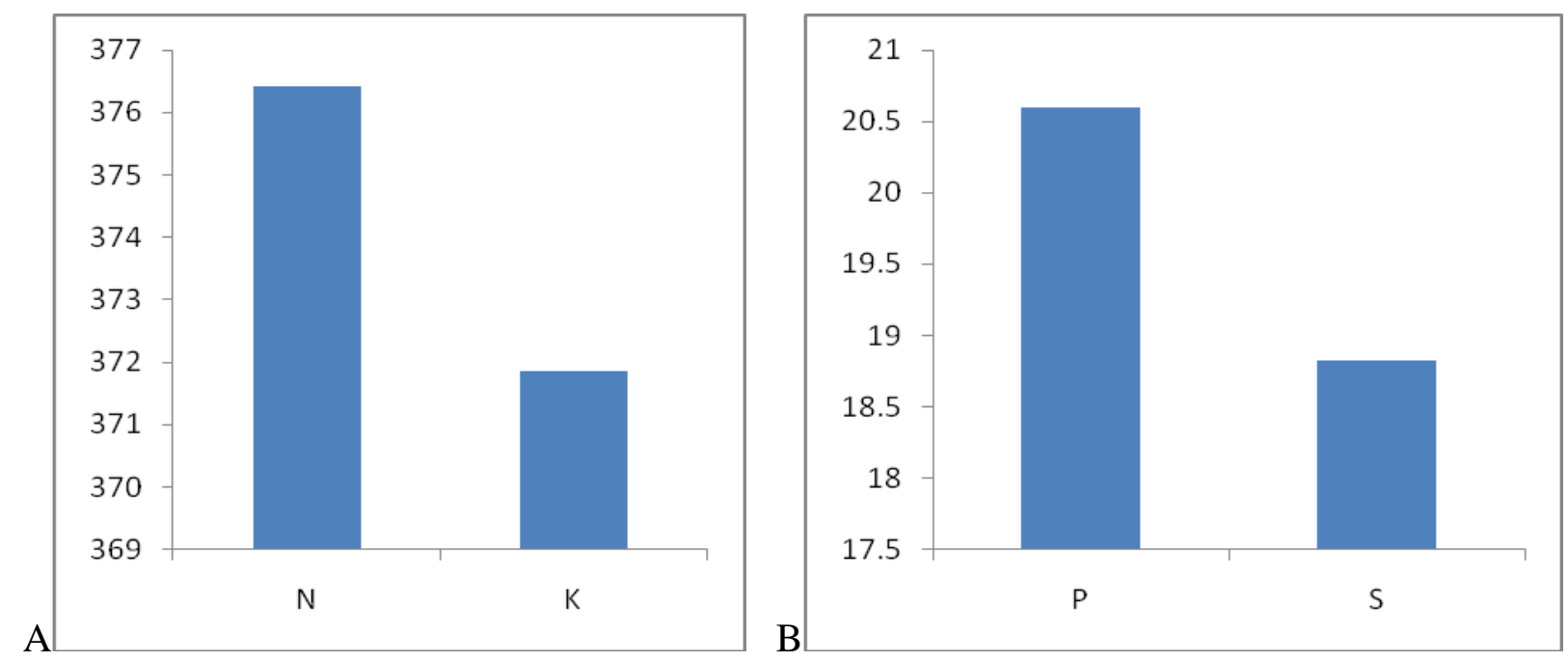

Fig.2 Graphical representation of the micro nutrients

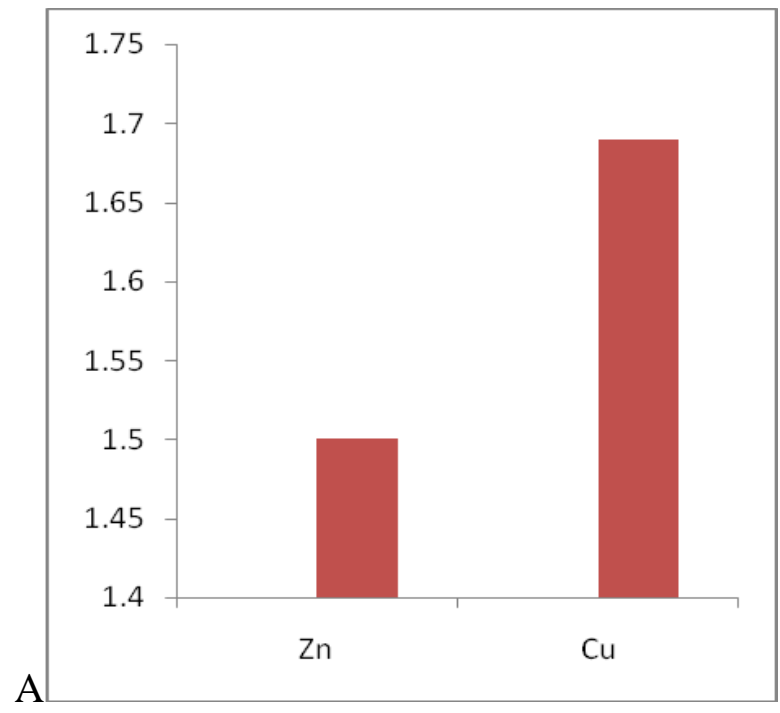

The available potassium (K) content exhibited medium to high status in all the profiles. The higher content of available potassium $(\mathrm{K})$ might be attributed to the high content of illitic type of clay in the soils of the catchment (Dhale and Prasad, 2009) and more intense weathering, release of labile organic residues, and upward translocation of potassium from lower depths along with capillary raise of ground water. Similar results were reported by Thangasamy et al., (2005) in soils of Chittor district.

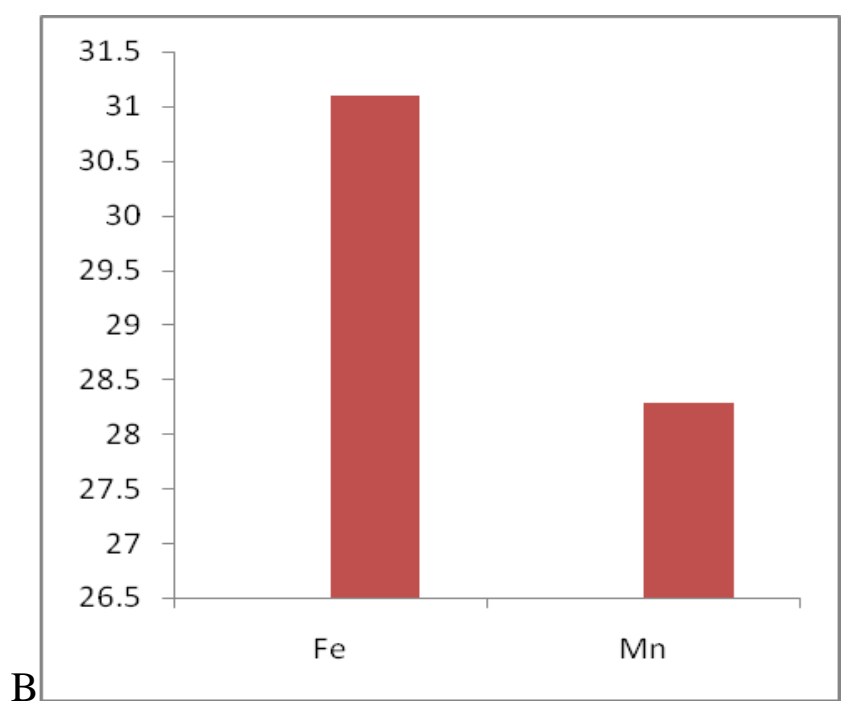

The variation in the sulphur content in surface and sub surface horizons might be due to varying land use and parent material. The available sulphur also showed a similar trend as shown by the potassium. High organic matter content in the surface horizons may be the reason for higher values of sulphur. Generally, the available $S$ has been observed in high concentration in top layers of profile due to continuous addition of farm residues, FYM and sulphur containing fertilizers (Patel and Patel, 2008). 
The content of zinc and copper varied from medium to high and decreased with the increase in depth in all the profiles. The content of $\mathrm{Zn}$ and $\mathrm{Cu}$ were in the range of 0.88 to $2.34 \mathrm{mg} \mathrm{kg}^{-1}$ and 0.97 to $2.66 \mathrm{mg} \mathrm{kg}^{-1}$ with a mean value of 1.50 to $1.69 \mathrm{mg} \mathrm{kg}^{-1}$, respectively. Whereas, iron and manganese contents were in the range of 18.45 to 42.26 $\mathrm{mg} \mathrm{kg}^{-1}$ and 15.12 to $40.06 \mathrm{mg} \mathrm{kg}^{-1}$ with a mean value of 31.10 and $28.28 \mathrm{mg} \mathrm{kg}^{-1}$ respectively. The data is shown in table 2 while as the graphical representation of the micro nutrients are shown in the figure $2 \mathrm{a}$ and b. While as the contents varied from medium to high and also decreased with the depth.

The variation observed in available micronutrient contents among different soils might be the result of variable intensity of different pedogenic processes taking place during soil development. Higher content of micronutrients in surface horizons may be due to the higher amount of organic carbon content which is ascribed to increase in the solubility of micronutrient cations from soil material. Decomposition of organic material releases micronutrients and also reduces $\mathrm{pH}$ locally which assists in mineral solubility. Further availability of metal ions $(\mathrm{Zn}, \mathrm{Cu}, \mathrm{Fe}$ and $\mathrm{Mn}$ ) increases as the organic matter provides chelating agent for complex formation of these micronutrients. Thus management of carbon stock will improve their availability to the plants (Kirmani et al., 2011). This corroborates similar observations made by Sangwan and Singh (1993), Sharma et al., (2000), Samndi et al., (2007) and Yadav and Meena (2009).

In conclusion nutrient distribution patterns resulting from plant activity suggest two opposing strategies for plants to obtain scarce nutrients. The first is to develop a dense root system in the topsoil, exploring the zone of maximum accumulation and intercepting nutrients as they move downward by leaching. The available nitrogen content was higher in surface horizons and showed gradual decrease with increasing depth, preferably due to decrease in organic carbon. Higher values of nitrogen were observed in some profiles due to high organic carbon content which was mostly influenced by vegetative cover and aspect. The available phosphorus, potassium and sulphur contents were in the higher range in all the soil profiles. All the soils showed decrease in available nutrient content with increasing depth which may be due to the nutrient recycling by the plants. Micronutrient ( $\mathrm{Zn}$, $\mathrm{Cu}, \mathrm{Fe}$ and $\mathrm{Mn}$ ) content was also in the higher range and a decreasing trend with the depth was observed in all the profiles. The control that plants exert on the vertical distribution of limiting nutrients can produce a strong positive feedback for plant productivity by enhancing resource availability

\section{References}

Buol, S.W., Hole, F.D. and McCracken, R.J. 1989. Soil Genesis and Classification, third edition.

Chesnin, L. and Yien, C.H. 1950. Turbidimetric determination of available sulphate. Soil Sci. Society American Procedure, 15: 149-151.

Dhale, S.A. and Prasad, J. 2009. Characterization and classification of sweet orange growing soils of Jalna district, Maharashtra. J. Indian Society of Soil Sci., 57(1): 11-17.

Hilgard, E. 1906. Soils, Their Formation, Properties, Compositions, and Relations to Climate and Plant Growth in the Humid and Arid Regions. Macmillan, New York, US.

Honeycutt, C.W., Heil, R.D. and Cole, C.V. 1990. Climatic and topographic relations of three Great Plains soils. I. Soil morphology. Soil Sci. Soc. Am. J., 54: 469-475. 
Jackson, M.L. 1973. Soil Chemical Analysis. Prentice Hall of India Private Limited, New Delhi, p. 498.

Jenny, H. 1941. Factors of soil Formation. McGraw-Hill, New York, US.

Kirby, M.J. 1985. A basis for soil profile modelling in a geomorphic context. $J$. Soil Sci., 36: 97- 121.

Lindsay, W.L. and Norvell, W.A. 1978. Development of DTPA soil test for Zinc, iron, manganese, and copper. Soil Sci. Society of American J., 42: 421-428

Marion, G.M. and Schlesinger, W.H. 1985. CALDEP: A regional model for soil $\mathrm{CaCO} 3$ (caliche) deposition in the southwestern deserts. Soil Sci., 139: 468-481.

Nazir, S. and Wani, M.A. 2009. Forms of potassium and potassium absorption behavior of soil under different cropping sequences. SKUAST J. Res., 11(2): 133-137.

Olsen, S.R. and Sommers, L.E. 1982. Phosphorus. Methods of soil analysis, Part 2 p. 403-430.

Rajeswar, M., and Khan, M.A.A. 2008. Characterization and classification of forest soils of Nizamabad district of Andhra Pradesh. An Asian J. soil Sci., 3(1): 11-16.

Selvaraj, S. and Naidu, M.V.S. 2012. Characteristics, Classification and Evaluation of soils for different land uses in Renigunta Mandal of Chittoor district in Andhra Pradesh. Ndian. $J$. Indian Society of Soil Sci., 60(3): 225229.

Singh, R.P. and Mishra, S.K. 2012. Available Macronutrients (N, P, K and S) in the soils of Chiraigaon block of District Varanasi (U.P.) in relation to Soil Characteristics. Indian J. Sci. Res., 3(1): 97-100.

Smeck, N.E. 1973. Phosphorus: an indicator of pedogenic weathering processes. Soil Sci., 115: 199-206.

Soil Survey Staff. 1975. Soil Taxonomy. USDA, Washington DC, US.

Subbiah, B.V. and Aaija, G.L. 1956. A rapid procedure for the estimation of availability nitrogen in soils. Curr. Sci., 25: 259-260.

Talib, A.R. and Verma, S.D. 1990. Relationship between different forms of potassium and particle size in bench mark soil of Kashmir. Indian J. Agri. Sci., 60(9): 643-644.

Thangasamy, A., Naidu, M.V.S., Ramavatharam, N. and Raghava R.C. 2005. Characterization, classification and evaluation of soil resources in Sivagiri micro-watershed of Chittoor district in Andhra Pradesh for sustainable land use planning. J. Indian Society of Soil Sci., 53: 11-21.

\section{How to cite this article:}

Mehraj ud din Khanday, D. Ram, J.A. Wani and Tahir Ali. 2017. Vertical Distribution of Nutrient of the Soils of Namblan Sub-Catchment of Jhelum Basin of Srinagar District in Kashmir Valley. Int.J.Curr.Microbiol.App.Sci. 6(4): 375-381. doi: https://doi.org/10.20546/ijcmas.2017.604.042 